\title{
Lidar observations of atmospheric internal waves in the boundary layer of the atmosphere on the coast of Lake Baikal
}

\author{
Viktor A. Banakh and Igor N. Smalikho \\ V.E. Zuev Institute of Atmospheric Optics SB RAS, Tomsk, Russia \\ Correspondence to: Viktor A. Banakh (banakh@iao.ru)
}

Received: 18 May 2016 - Published in Atmos. Meas. Tech. Discuss.: 22 June 2016

Revised: 11 October 2016 - Accepted: 12 October 2016 - Published: 27 October 2016

\begin{abstract}
Atmospheric internal waves (AIWs) in the boundary layer of atmosphere have been studied experimentally with the use of Halo Photonics pulsed coherent Doppler wind lidar Stream Line. The measurements were carried out over 14-28 August 2015 on the western coast of Lake Baikal $\left(51^{\circ} 50^{\prime} 47.17^{\prime \prime} \mathrm{N}, 104^{\circ} 53^{\prime} 31.21^{\prime \prime} \mathrm{E}\right)$, Russia. The lidar was placed at a distance of $340 \mathrm{~m}$ from Lake Baikal at a height of $180 \mathrm{~m}$ above the lake level.

A total of six AIW occurrences have been revealed. This always happened in the presence of one or two (in five out of six cases) narrow jet streams at heights of approximately 200 and $700 \mathrm{~m}$ above ground level at the lidar location. The period of oscillations of the wave addend of the wind velocity components in four AIW events was $9 \mathrm{~min}$, and in the other two it was approximately 18 and $6.5 \mathrm{~min}$. The amplitude of oscillations of the horizontal wind velocity component was about $1 \mathrm{~m} \mathrm{~s}^{-1}$, while the amplitude of oscillations of the vertical velocity was 3 times smaller. In most cases, internal waves were observed for $45 \mathrm{~min}$ ( 5 wave oscillations with a period of $9 \mathrm{~min}$ ). Only once the AIW lifetime was about $4 \mathrm{~h}$.
\end{abstract}

\section{Introduction}

Atmospheric gravity waves (AGWs) are an important feature of motions present in the atmosphere. They are responsible for the transfer of additional mechanic and thermal energy, which leads to the spatial inhomogeneity and temporal variability of the wind and temperature fields. As AGWs are destroyed, the released energy causes turbulence of the wind and temperature fields. A detailed review of work on this subject was carried out recently by Plougonven and Zhang (2014) and by Sun et al. (2015).

Studies of the gravity waves are carried out with the help of space images of the cloud fields in the visible and microwave regions (for example, German, 1985; Li et al., 2001) and radar images of the sea surface (for example, Spiridonov et al., 1987; Chunchuzov et al., 2000). Experimental investigations of AGWs in the ionosphere from the scattering of radio waves are carried out using different methods (for example, Benediktov et al., 1997). The first results of lidar observations of the internal gravity waves in the stratosphere and mesosphere with the use of the Doppler Rayleigh lidar are reported in Baumgarten et al. (2015). An airborne $2 \mu \mathrm{m}$ coherent Doppler wind lidar was used by Chouza et al. (2016) to research island-induced gravity waves.

AGW observations in the lower atmosphere, in particular in the atmospheric boundary layer (ABL), are based mostly on fixed-point or mobile platform pressure measurements (Román-Cascón et al., 2015; Sun et al., 2015). For studying AGW, coherent Doppler wind lidars (CDWLs) and sodars are used as well. Newsom and Banta (2003) and Wang et al. (2013) applied $2 \mu \mathrm{m}$ CDWL to investigate of low-level jet and gravity waves in the stable ABL over flat and urban terrains, respectively. Lyulyukin et al. (2015) observed AGW in the lower atmospheric layer (300-400 m) based on sodar data. However, the data of lidar and sodar observations of AGW in the ABL are few and far between.

In this paper we present the results of lidar observations of the coastal-mountain lee waves on the coast of Lake Baikal. Lee AIWs (or orographic waves) are one of the types of AGWs, which arise leeward of obstacles at the stable stratification of an incoming flow (Vel'tishchev and Stepanenko, 2006; Kozhevnikov, 1999; Makarenko and Maltseva, 
Table 1. Main parameters of the HALO Photonics Stream Line lidar.

\begin{tabular}{ll}
\hline Wavelength & $1.5 \mu \mathrm{m}$ \\
Pulse energy & $14 \mu \mathrm{J}$ \\
Pulse duration & $170 \mathrm{~ns}$ \\
Pulse repetition frequency & $15 \mathrm{kHz}$ \\
Initial beam diameter $\left(e^{-2}\right)$ & $5.6 \mathrm{~cm}$ \\
Focus length & $\geq 300 \mathrm{~m}$ \\
Telescope diameter & $8 \mathrm{~cm}$ \\
Sampling frequency (length) & $50 \mathrm{MHz}(3 \mathrm{~m})$ \\
Nyquist velocity & $\pm 19.5 \mathrm{~m} \mathrm{~s}^{-1}$ \\
Minimum range & $90 \mathrm{~m}$ \\
Maximum range & $9600 \mathrm{~m}$ \\
\hline
\end{tabular}

2011). Experimental investigations of AIWs in the atmospheric boundary layer of Lake Baikal were carried out with the use of the $1.5 \mu \mathrm{m}$ Halo Photonics CDWL Stream Line (Pearson et al., 2009). These lidars find expanding applications in studies of ABL (O'Connor et al., 2010; Sathe and Mann, 2012; van Dinther et al., 2015; Päschke et al., 2015; Smalikho and Banakh, 2015a, b; Smalikho et al., 2015a, b, c; Vakkari et al., 2015).

The processing of all data measured by the lidar and the analysis of the processed data have revealed several cases of formation of atmospheric internal waves for the period of measurements. Formation of one, and often simultaneously two, narrow jet streams at heights of the atmospheric boundary layer were observed as well. In all cases, AIWs were formed in the presence of low-level jet streams.

\section{Lidar, measurement strategy and data processing}

The main parameters of lidar Stream Line used in the experiment on the shore of Lake Baikal are given in Table 1. Despite the low energy of the probing pulse, relatively high pulse repetition frequency $f_{\mathrm{P}}$ allows one to use a large number of laser shots $N_{\mathrm{a}}$ for the accumulation of raw lidar data and obtain estimations of radial velocity with required accuracy and time resolution.

Measurement strategy of this lidar was as follows. During the experiment we used the conical scanning (see Fig. 1). At a fixed elevation angle $\varphi$ the probing laser beam was rotated continuously around the vertical axis $Z$ with the angular speed $\omega_{\mathrm{s}}=2 \pi / T_{\text {scan }}$, where $T_{\text {scan }}$ is the duration of one full scan, starting from the azimuth angle $\theta=0^{\circ}$ to $\theta=360^{\circ}$. Then, the laser beam was stopped and after $0.3 \mathrm{~s}$ it began a continuous rotation in the opposite direction to the angle $\theta=0^{\circ}$. After $0.3 \mathrm{~s}$ the cycle was repeated. The above procedure was executed continuously during the experiment.

For lidar observation of the atmospheric gravity waves in the atmospheric boundary layer, the scan time $T_{\text {scan }}$ and the diameter of the scan cone base should be set as small as possible. The scan cone base diameter $d=2 R \cos \varphi$ at the dis-

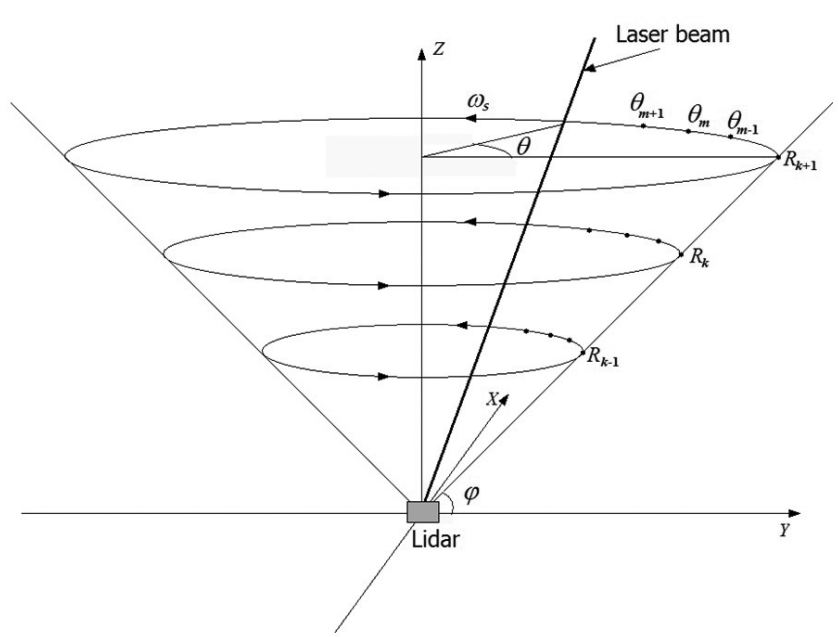

Figure 1. Geometry of measurement by a pulsed coherent Doppler lidar with the conical scanning by the laser beam.

tance $R$ from the lidar depends on the beam elevation angle $\varphi$. With $\varphi \rightarrow 90^{\circ}$ (for decreasing the scan cone base) the error of estimation of horizontal components of the wind vector $\boldsymbol{V}=\left\{V_{z}, V_{x}, V_{y}\right\}$, where $V_{z}$ is the vertical component, increases indefinitely due to wind turbulence and random instrumental errors of estimation of the radial velocity $V_{\mathrm{r}}$. The lower the signal-to-noise ratio SNR (ratio of the mean signal power to the mean noise power for fixed range $R$ ), the greater the increase in error. In our experiment, we set the elevation angle to $\varphi=60^{\circ}$ at which the height above the lidar was $h=d$.

Taking into account that the typical period of the atmospheric gravity wave is at least several minutes, we set $T_{\text {scan }}=36 \mathrm{~s}$. At $N_{\mathrm{a}}=3000$ (measurement duration $T_{\text {ray }}=$ $N_{\mathrm{a}} / f_{\mathrm{P}}=0.2 \mathrm{~s}$ ), after data preprocessing by the lidar internal PC, for one full scan we have arrays of estimates of the radial velocity $\hat{V}_{\mathrm{r}}\left(R_{k}, \theta_{m}\right)$ and the signal-to-noise ratio $\operatorname{SNR}\left(R_{k}, \theta_{m}\right)$ for $M=T_{\text {scan }} / T_{\text {ray }}=180$ rays, where $R_{k}=R_{0}+k \Delta R$ is the current range, $R_{0}=105 \mathrm{~m}, k=$ $0,1,2,3, \ldots, K-1, K=63, \Delta R=30 \mathrm{~m}, \theta_{m}$ is the azimuth angle, $m=1,2,3, \ldots, M$ (ideally, for increasing angle $\theta_{m}=$ $m \Delta \theta$ and $\Delta \theta=2^{\circ}$ ). The range $R_{k}$ corresponds to the height above ground level (a.g.l.) $h_{k}=R_{k} \sin \varphi$. All measurement parameters are given in Table 2.

From the array $\hat{V}_{\mathrm{r}}\left(R_{k}, \theta_{m}\right)$ measured at $\varphi=60^{\circ}$ and relatively high SNR (when probability of a "bad" or unreliable estimate of the radial velocity is very small), one can obtain an acceptable estimate of the wind vector $\hat{\boldsymbol{V}}=$ $\left\{\hat{V}_{z}, \hat{V}_{x}, \hat{V}_{y}\right\}$, using the fitting of $\boldsymbol{S}\left(\theta_{m}\right) \cdot \boldsymbol{V}$, where $\boldsymbol{S}\left(\theta_{m}\right)=$ $\left\{\sin \varphi, \cos \varphi \cos \theta_{m}, \cos \varphi \sin \theta_{m}\right\}$, to the array $\hat{V}_{\mathrm{r}}\left(R_{k}, \theta_{m}\right)$ by the least-squares method (LSM). To judge the acceptability of this estimate, it is necessary to know the threshold $\mathrm{SNR}_{t}$ that depends, in particular, on $N_{\mathrm{a}}$.

To obtain the results represented in Sect. 3, we used the filtered sine-wave fitting (FSWF) (Smalikho, 2003; Banakh 
Table 2. Measurement parameters.

\begin{tabular}{ll}
\hline Range gate length & $30 \mathrm{~m}$ \\
Number of points per range gate & 10 \\
Elevation angle & $60^{\circ}$ \\
Height resolution & $26 \mathrm{~m}$ \\
Number of pulses for accumulation & 3000 \\
Integration time per ray & $0.2 \mathrm{~s}$ \\
Focus length & $800 \mathrm{~m}$ \\
Velocity resolution & $0.0382 \mathrm{~m} \mathrm{~s}^{-1}$ \\
Scanning speed & $10^{\circ} \mathrm{s}^{-1}$ \\
Azimuth angle resolution & $2^{\circ}$ \\
Number of rays per scan & 180 \\
Duration of one scan & $36 \mathrm{~s}$ \\
\hline
\end{tabular}

et al., 2010, 2015; Banakh and Smalikho, 2013). This method is based on finding the maximum of the function

$Q(\boldsymbol{V})=\sum_{m=1}^{M} \exp \left\{-\left[\hat{V}_{\mathrm{r}}\left(R_{k}, \theta_{m}\right)-\boldsymbol{S}\left(\theta_{m}\right) \cdot \boldsymbol{V}\right]^{2} /\left(2 \sigma^{2}\right)\right\}$,

where $\sigma$ is the filtration parameter (we set $\sigma=2 \mathrm{~m} \mathrm{~s}^{-1}$ ), that is, $\max \{Q(\boldsymbol{V})\}=Q(\hat{\boldsymbol{V}})$ at each height $h_{k}$ sequentially. In contrast to the LSM, the FSWF filters "good" (reliable) estimates $\hat{V}_{\mathrm{r}}\left(R_{k}, \theta_{m}\right)$, when $\hat{\boldsymbol{V}}$ is true, at very low SNR. At high SNR and correctly chosen $\sigma \geq 2 \mathrm{~m} \mathrm{~s}^{-1}$, the LSM and FSWF give similar results even in the case of strong wind turbulence. From the estimate of wind velocity vector $\hat{\boldsymbol{V}}$ the horizontal wind velocity $U$ and the wind direction angle $\theta_{V}$ are calculated.

Figure 2 shows an example of wind profiles $U\left(h_{k}\right)$, $\theta_{V}\left(h_{k}\right)$ and $\hat{V}_{z}\left(h_{k}\right)$ retrieved from data measured by the Stream Line lidar on the shore of Lake Baikal, $25 \mathrm{Au}$ gust 2015 at 23:15:30 LT (local time) (here and in other figures the height is above the lidar position level). For the retrieval of wind profiles in Fig. 2 we used both LSM and FSWF methods. The figure also shows the profile of the estimate of the signal-to-noise ratio obtained from the same measurement and averaged over all the rays: $\operatorname{SNR}\left(h_{k}\right)=$ $M^{-1} \sum_{m=1}^{M} \operatorname{SNR}\left(R_{k}, \theta_{m}\right)$. It is seen from the figure that both these methods give similar results, except for a layer of 600 $900 \mathrm{~m}$ and a layer over $1400 \mathrm{~m}$. Due to the filtration of data, the FSWF provides more smooth profiles of the wind in the layers $600-900$ and $1400-1500 \mathrm{~m}$ than the LSM. This proves a greater effectiveness of the FSWF compared to the LSM.

The mean noise power is a function of the range $R$ (Manninen et al., 2016). Therefore, at very low signal-to-noise ratios, the estimate $\mathrm{S} \overline{\mathrm{N}} \mathrm{R}\left(h_{k}\right)$ has a systematic error (in particular, $S \bar{N} R$ can take negative values). This does not allow us to find an adequate threshold $\mathrm{SNR}_{t}$ without the special procedure of data correction (Manninen et al., 2016). To correct the measured profile $\mathrm{S} \overline{\mathrm{N}} \mathrm{R}\left(h_{k}\right)$, first we use a smoothing cubic spline fit to all $\mathrm{S} \overline{\mathrm{N}} \mathrm{R}\left(h_{k}\right) \leq 0.015$ and obtain the function $\mathrm{SNR}_{\mathrm{S}}\left(h_{k}\right)$ (see green squares in Fig. 2d). Then, assuming
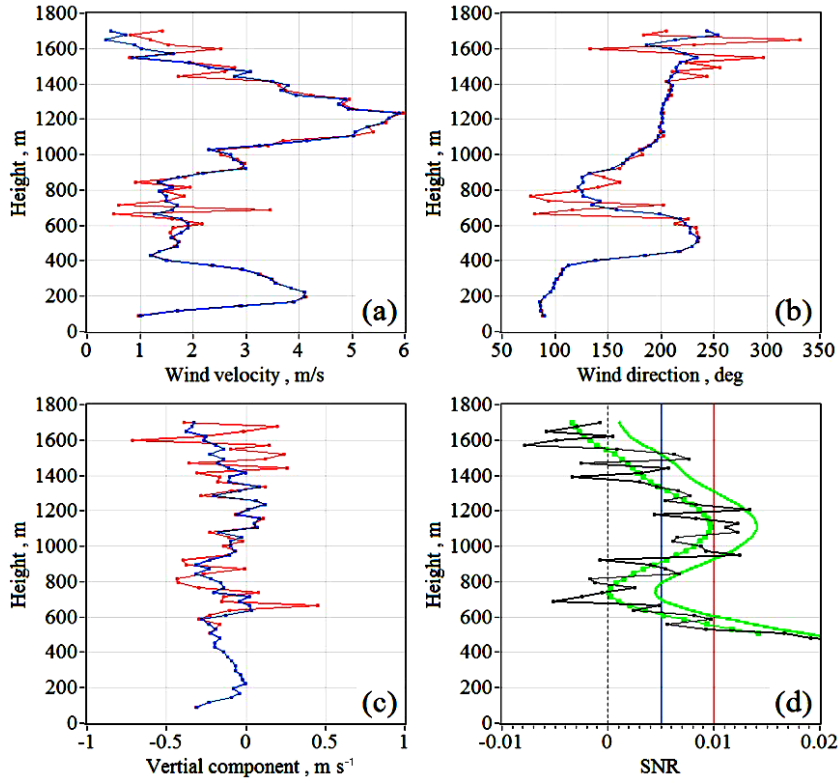

Figure 2. Height profiles of wind velocity (a), wind direction angle (b) and vertical component the wind vector (c) retrieved from data measured by the Stream Line lidar, using LSM (red curves) and FSWF (blue curves); (d): height profiles of signal-to-noise ratio estimates $\mathrm{S} \overline{\mathrm{N}} \mathrm{R}$ (black curve), $\mathrm{SNR}_{\mathrm{S}}$ (green squares) and $\mathrm{SNR}_{\mathrm{c}}$ (green solid curve).

that at some heights $h_{k}$, the true SNR is very close to zero, we find the minimum of the function $\operatorname{SNR}_{\mathrm{s}}\left(h_{k}\right)$ and obtain a corrected profile of the signal-to-noise ratio in the form:

$\operatorname{SNR}_{\mathrm{c}}\left(h_{k}\right)=\operatorname{SNR}_{\mathrm{s}}\left(h_{k}\right)-\min \left\{\mathrm{SNR}_{\mathrm{s}}\left(h_{k}\right)\right\}+\mathrm{SNR}_{\min }$,

where $\mathrm{SNR}_{\min }$ is the unknown true minimal SNR. We note that in practice the heights of $\min \left\{\mathrm{SNR}_{\mathrm{S}}\left(h_{k}\right)\right\}$ and $\mathrm{SNR}_{\min }$ can be different.

To avoid needing to determine $\mathrm{SNR}_{\min }$, we proceeded as follows. From our measurements from the Stream Line lidar in Tomsk in September 2015 (focus length was 300 m; the measurements were carried out in clear weather without clouds) using the raw data (in binary files for correlation functions of the complex lidar signal), we obtained the following function:

$N(R)=\left[P_{\mathrm{N}}(R)-\bar{P}_{\mathrm{N}}\right] / \bar{P}_{\mathrm{N}}$,

where $P_{\mathrm{N}}(R)$ is the mean noise power as a function of range $R$ and $\bar{P}_{\mathrm{N}}$ is the noise power averaged over an interval from 1 to $3 \mathrm{~km}$. An example of the function $N(R)$ is shown in Fig. 3. According to the figure, in the interval $1-2 \mathrm{~km}$ the function $N(R)$ has regular oscillations with amplitude $A \sim 0.001$ and range period $L \sim 450 \mathrm{~m}$ (at elevation angle $\varphi=60^{\circ}$ the height period $L \sin \varphi-400 \mathrm{~m}$ ).

Let us assume that $\mathrm{SNR}_{\min }=0.001$. The result of calculation by Eq. (2) at $\mathrm{SNR}_{\min }=0.001(-30 \mathrm{~dB})$ is shown in Fig. $2 \mathrm{~d}$ as a green solid curve. If assumption $\mathrm{SNR}_{\min }=0.001$ 


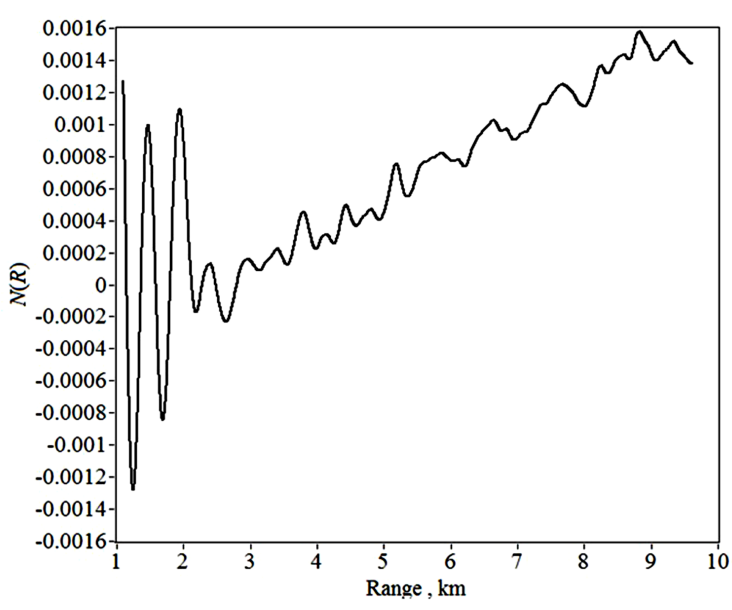

Figure 3. Function $N(R)$.

is correct, then the threshold signal-to-noise ratios can be set as $\mathrm{SNR}_{t}=0.005(-23 \mathrm{~dB})$ in the case of FSWF and $\mathrm{SNR}_{t}=0.01(-20 \mathrm{~dB})$ in the case of LSM. These thresholds are found from the profiles shown in Fig. $2 \mathrm{a}-\mathrm{c}$ and depicted in Fig. $2 \mathrm{~d}$ as blue and red lines, respectively. In the paper of Päschke at al. (2015) the authors assert that the decrease of the threshold SNR from 0.015 down to 0.01 would increase the data availability by almost $40 \%$. It corresponds to the LSM profiles presented in Fig. 2a-c. Since in the experiments on Lake Baikal we used the FSWF for processing the data, we could use the value $\mathrm{SNR}_{t}=0.005-\mathrm{SNR}_{\min }=$ $0.005-0.001=0.004$ as the SNR threshold. Taking into account that regular oscillations of SNR of our lidar have maximal amplitude $A \sim 0.001$ (Fig. 3), upon obtaining the results presented below, we rejected the wind estimates that do not satisfy the following condition:

$\mathrm{SNR}_{\mathrm{s}}\left(h_{k}\right)-\min \left\{\operatorname{SNR}_{\mathrm{s}}\left(h_{k}\right)\right\} \geq 0.005$,

where information about $\mathrm{SNR}_{\min }$ is not required. In colour figures of this paper, the rejected estimates are shown in black.

\section{Observations and analysis}

The measurements were conducted over 14-28 August 2015 on the western coast of Lake Baikal $\left(51^{\circ} 50^{\prime} 47.17^{\prime \prime} \mathrm{N}\right.$, $104^{\circ} 53^{\prime} 31.21^{\prime \prime} \mathrm{E}$ ) in the area of the Baikal Astrophysical Observatory of the Institute of Solar-Terrestrial Physics SB RAS, near the Baikal Solar Vacuum Telescope (BSVT). The lidar was set at a minimum distance of $340 \mathrm{~m}$ from Baikal at a height of $180 \mathrm{~m}$ above the lake level (see Fig. 4). According to Google Maps, the profile of the relief surface of the earth, starting from the position of the lidar and going in a northward direction up to $30 \mathrm{~km}$, has 10 local maxima with heights of $180-420 \mathrm{~m}$ and the same number of minimums with heights of $60-250 \mathrm{~m}$ above the level of Lake Baikal.
Due to forest fires, the atmosphere often contained greater amounts of aerosol and, correspondingly, the lidar signal-tonoise ratio was rather high.

Figure 5 shows the results of lidar visualisation of the wind field during the longest observations of a gravity wave for about $4 \mathrm{~h}$ starting from 12:00 LT 23 August 2015. Two jet streams were observed simultaneously at heights of about 250 and $750 \mathrm{~m}$ a.g.l. The direction of the first jet stream (at height of $250 \mathrm{~m}$ ) was from north to south and the direction of the other one was from east to west.

Figures 6 and 7 show the vertical profiles at 14:31 LT and temporal profiles at a height of $636.5 \mathrm{~m}$ a.g.l. of wind taken from data in Fig. 5. From these figures, we can clearly see oscillations of the wind speed, direction and vertical component in both height and time. They are especially evident during the period from 13:30 to 15:30 LT, when the amplitude of oscillations of the wind direction is maximal and equal to approximately $45^{\circ}$.

Neglecting the wind turbulence, we use the model of a plane wave for the component of the wind velocity vector $V_{\alpha}$ (subscript $\alpha=z$ for the vertical component, $\alpha=x$ for the longitudinal component and $\alpha=y$ for the transverse component) in the form (Vinnichenko et al., 1973):

$V_{\alpha}(\boldsymbol{r}, t)=<V_{\alpha}>+\widetilde{V}_{\alpha}(\boldsymbol{r}, t)$.

In Eq. (5) $\boldsymbol{r}=\{z, x, y\}$ is the radius vector in the Cartesian system with the coordinates of the centre at the lidar position, $t$ is time, $<V_{\alpha}>$ and $\widetilde{V}_{\alpha}$ are the regular and wave addends of the $\alpha$-th component of the wind velocity, respectively.

$\tilde{V}_{\alpha}(\boldsymbol{r}, t)=A_{\alpha}(z) \sin \left[\psi_{\alpha}(\boldsymbol{r})-2 \pi t / T_{v}\right]$

$A_{\alpha}$ is the wave amplitude, $\psi_{\alpha}$ is the wave phase and $T_{v}$ is the wave period. If the wind direction coincides with the direction of propagation of the internal gravity wave, then $A_{y}=0$, $\psi_{x}=2 \pi x / \lambda_{v}$ and $\psi_{z}=2 \pi x / \lambda_{v}+\pi / 2$ (Vinnichenko et al., 1973). Here, $\lambda_{v}$ is the wavelength of the wave propagating with the speed $c_{v}=\lambda_{v} / T_{v}$.

Models (5) and (6) were applied to the analysis of data in Fig. 5 for a height of $766.4 \mathrm{~m}$ a.g.l. (inside the upper jet stream) and 47 min time interval starting from 14:20 LT, when the amplitude of wind velocity oscillations was maximal. From these data, with allowance made for the linear trend, we found the wave addends $\widetilde{V}_{\alpha}(\boldsymbol{r}, t)$ for the three components of the wind velocity vector. In Fig. 8, the solid curve shows the dependence of $\widetilde{V}_{x}$ on $t$. To determine the wave frequency $f_{v}=1 / T_{v}$, we have used experimental function $\widetilde{V}_{x}(t)$ and calculated the spectral density, which is depicted in Fig. 9.

The obtained spectrum has a peak, from which position we have determined the frequency $f_{v}$ to be equal to $0.00185 \mathrm{~Hz}$. Consequently, the wave period is $T_{v}=9 \mathrm{~min}$. Using the leastsquares fitting of model (6) for $\widetilde{V}_{x}(t)$ to the wave addend of the wind velocity component measured by the lidar (solid curve in Fig. 8), we have determined the phase $\psi_{x}$ and the 


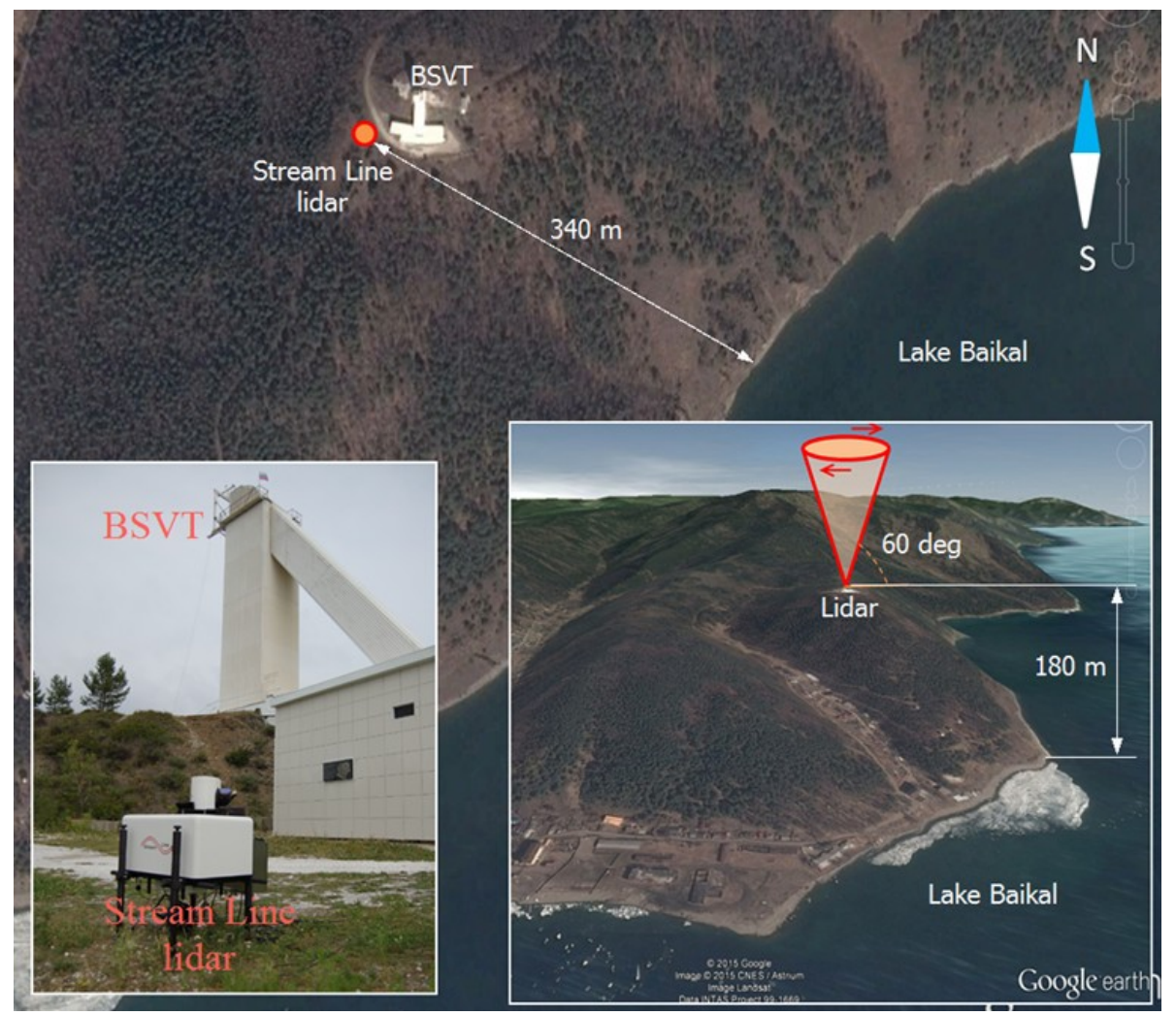

Figure 4. Map of lidar wind measurements over 14-28 August 2015.

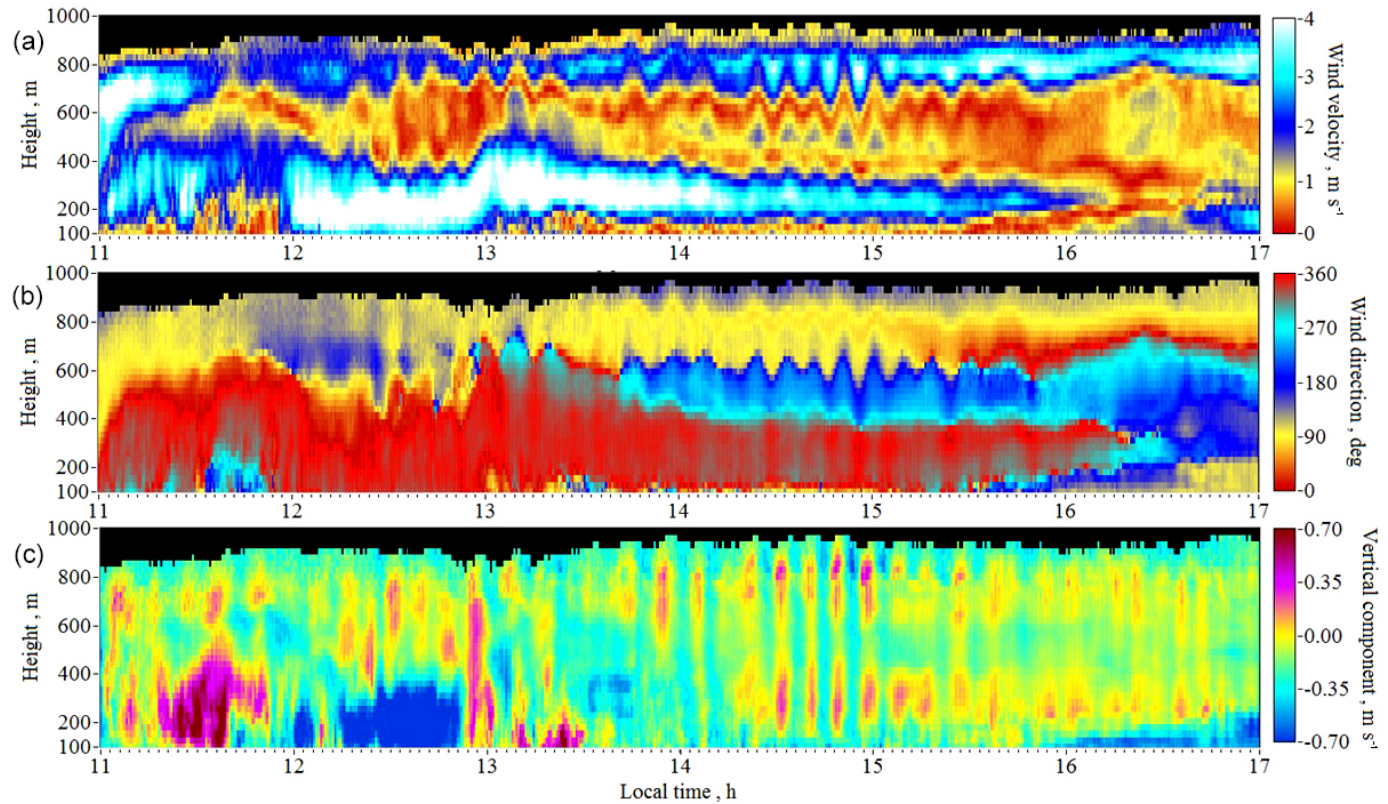

Figure 5. Spatio-temporal distributions of the wind speed (a), the wind direction angle (b) and the vertical component of the wind vector (c) obtained from measurements with the Stream Line lidar on 23 August 2015. 

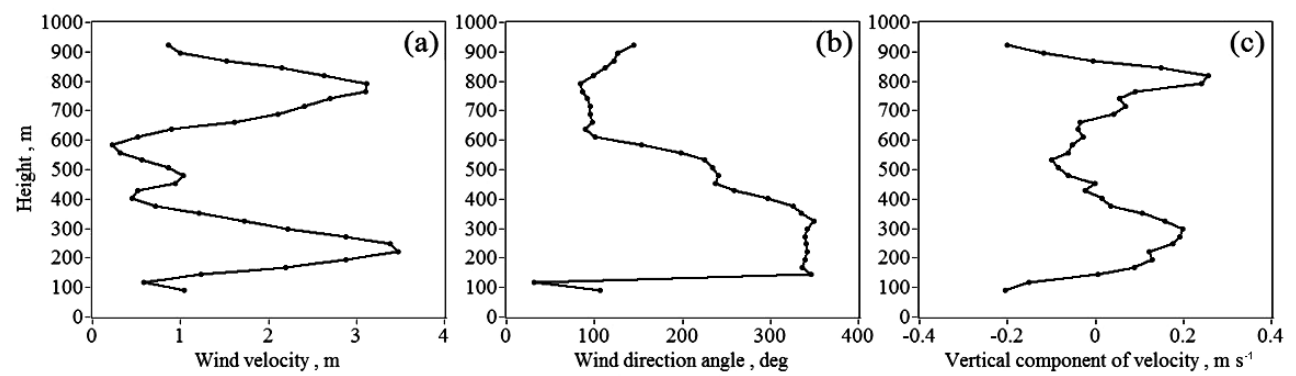

Figure 6. Vertical profiles of the wind speed (a), the wind direction angle (b) and the vertical component of the wind vector (c) taken from the data of Fig. 4 (these profiles were measured at 14:31 LT).

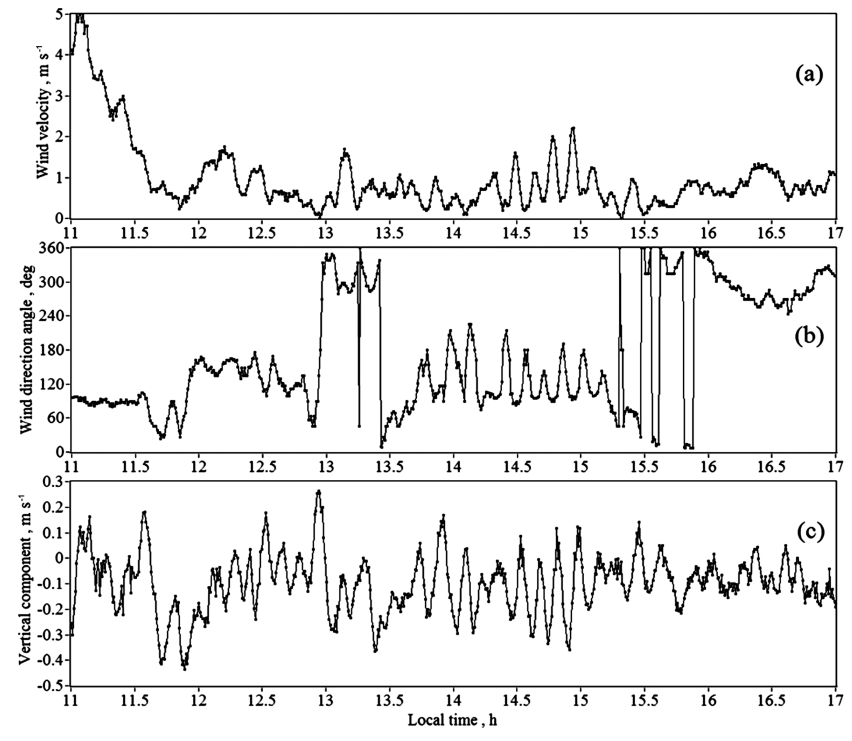

Figure 7. Temporal profiles of the wind speed (a), the wind direction angle (b) and the vertical component of the wind velocity (c) taken from the data of Fig. 5 (measurement height of $636.5 \mathrm{~m})$.

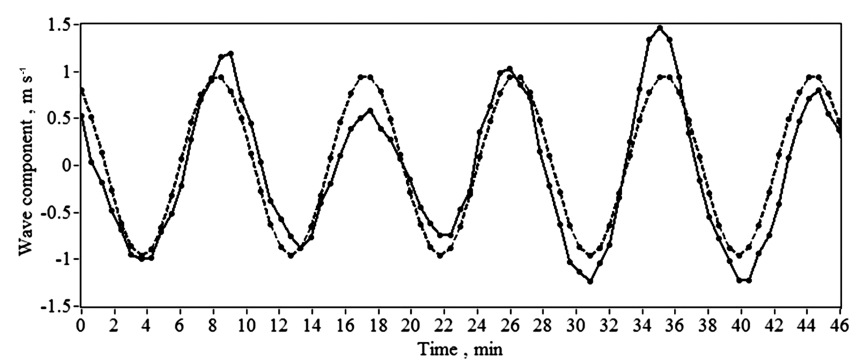

Figure 8. Time dependence of the wave addend of the longitudinal wind velocity: (solid curve) measurements by the Stream Line lidar starting from 14:20 LT on 23 August 2015 at a height of $766.4 \mathrm{~m}$ a.g.1. (the data of Fig.5a were used); (dashed curve) result of least-squares fitting of sine-wave dependence (6) for the wave addend $\widetilde{V}_{x}(t)$ to the measured data shown by the solid curve.

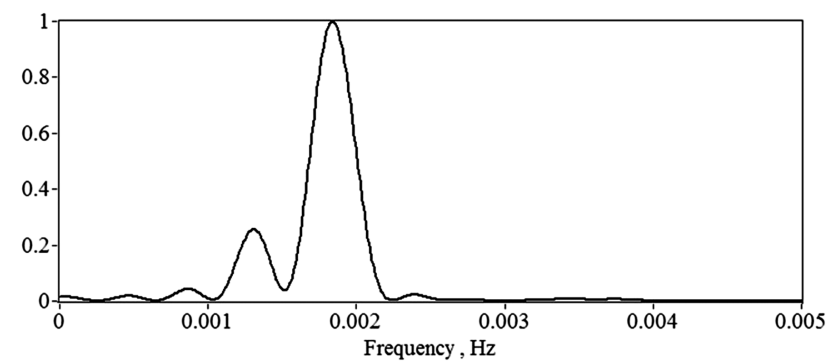

Figure 9. Normalised spectrum of the wave addend of wind velocity calculated from the data shown by the solid curve in Fig. 8 .

amplitude $A_{x}$. The amplitude of wave addend for the longitudinal component of the wind velocity vector turned out to be $0.96 \mathrm{~m} \mathrm{~s}^{-1}$. The model temporal profile $\widetilde{V}_{x}(t)$ calculated by Eq. (6) with the use of experimental values of $A_{x}, \psi_{x}$ and $T_{v}$ is shown as a dashed curve in Fig. 8.

Parameters of the wave addend of the vertical wind velocity $\widetilde{V}_{z}(t)$ were found in the same way. The estimates of periods of the internal wave for the longitudinal and vertical components coincided fully ( $\left.T_{v}=9 \mathrm{~min}\right)$, amplitude $A_{z}=$ $0.3 \mathrm{~m} \mathrm{~s}^{-1}$ is approximately 3 times smaller than the amplitude of wave addend of the longitudinal component of the wind velocity vector and $\psi_{z}-\psi_{x}=\pi / 2$. Since the amplitude $A_{y} \neq 0$ (see Figs. $5 \mathrm{~b}$ and $7 \mathrm{~b}$ ), the direction of propagation of the internal wave did not coincide with the wind direction.

To estimate the wind turbulence strength during observation of the AIW, we used the array of radial velocities measured from 14:20 to 15:20 LT on 23 August 2015 and retrieved a vertical profile of the turbulent energy dissipation rate $\varepsilon$ in the layer $200-500 \mathrm{~m}$ a.g.l. using the method described in paper by Smalikho et al. (2015c). Obtained values $\varepsilon$ are rather small and decrease with height from $3 \times 10^{-5} \mathrm{~m}^{2} \mathrm{~s}^{-13}$ at $200 \mathrm{~m}$ to approximately $10^{-5} \mathrm{~m}^{2} \mathrm{~s}^{-13}$ at $500 \mathrm{~m}$. To calculate the contribution of the turbulence into variation of lidar estimates of the wind velocity, it is necessary to know, at least, the integral scale of the longitudinal wind velocity correlation $L_{\mathrm{I}}$. Unfortunately, the measurement geometry used in the experiment did not allow us to obtain estimation of $L_{\mathrm{I}}$ from the measured lidar data. Due to the 


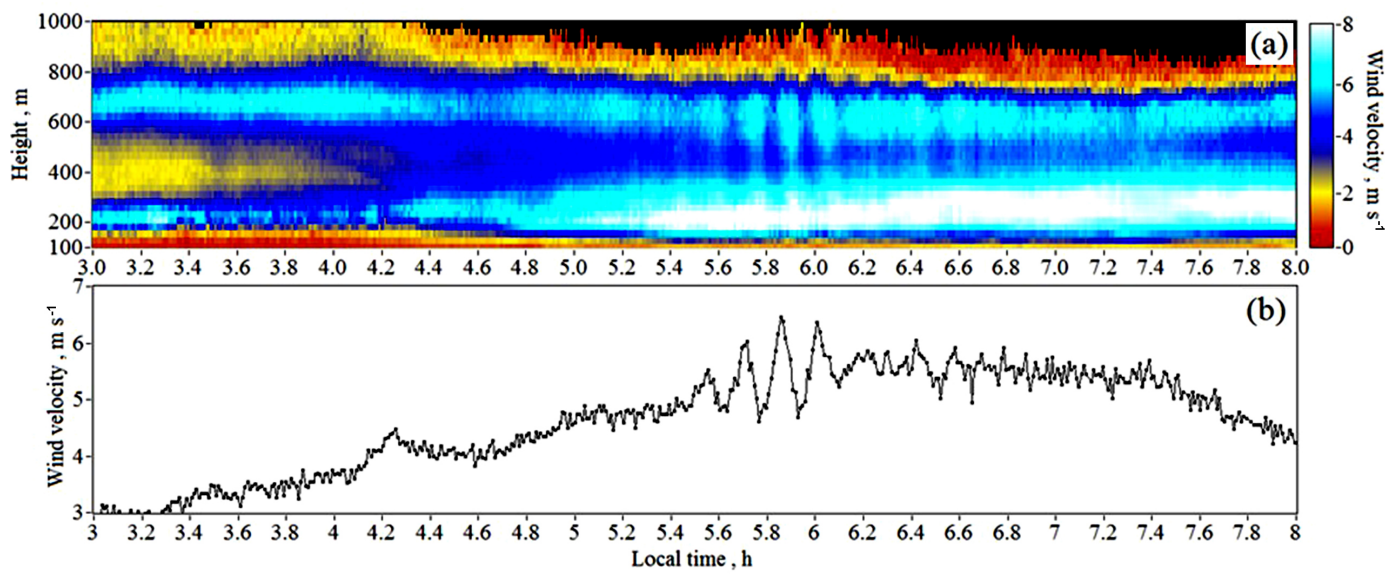

Figure 10. Spatio-temporal distribution of the wind velocity (a) and the time profile of the wind velocity at a height of $532.6 \mathrm{~m}$ a.g.1. (b) obtained from measurements by the Stream Line lidar on 20 August 2015.
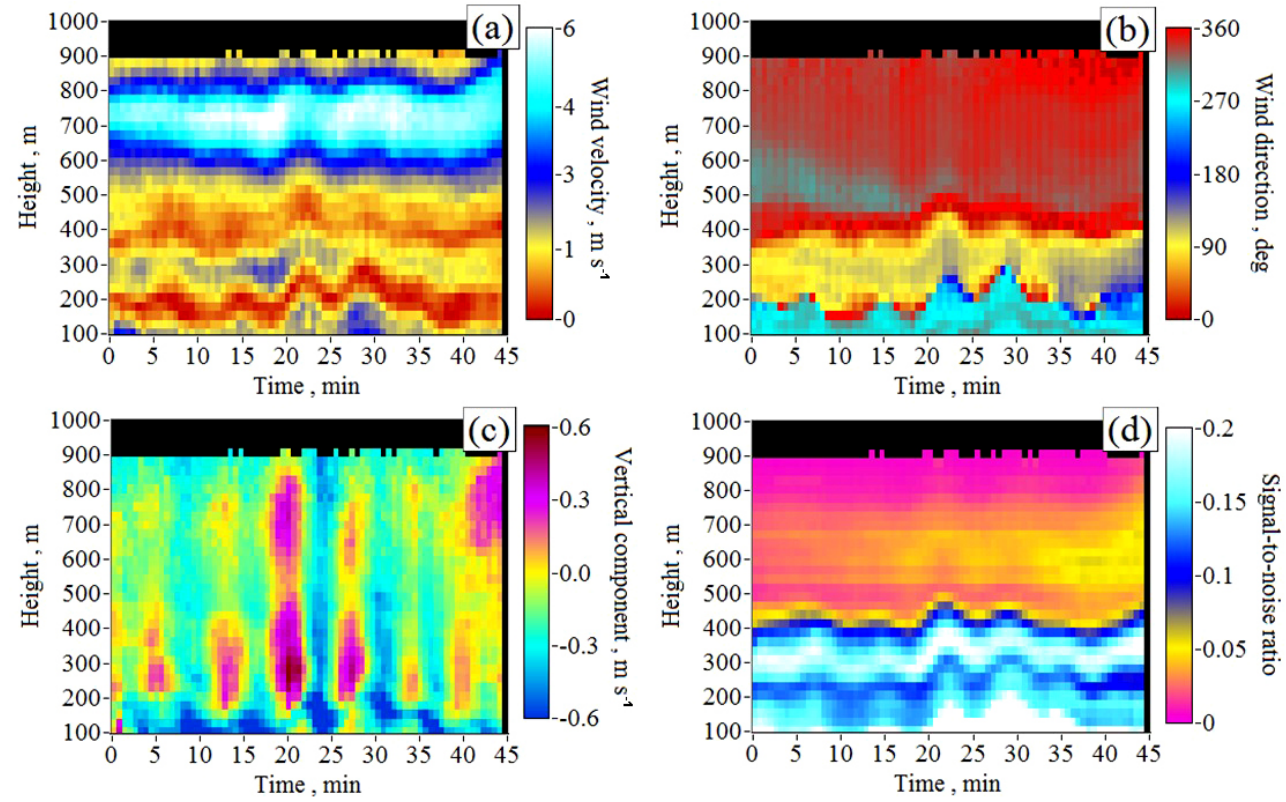

Figure 11. Spatio-temporal distributions of the wind speed (a), wind direction angle (b), vertical component of the wind vector (c) and signal-to-noise ratio (d) obtained from measurements of the Stream Line lidar on 14 August 2015 starting from 19:24 LT.

filtration (see Sect. 2) the instrumental error of the wind velocity estimate, obtained at $M=180$ and with a SNR threshold 0.005 (Eq. 4), does not exceed $0.1 \mathrm{~m} \mathrm{~s}^{-1}$. In our experiment for heights $h<500 \mathrm{~m}$ a.g.l., it did not usually exceed $0.05 \mathrm{~m} \mathrm{~s}^{-1}$. For the vertical wind component the instrumental error is approximately 3 times smaller.

Figures 5-7 illustrate the long time AIW in the case of weak wind, when wind velocity averaged over the period $T_{v}$ is $1-2.5 \mathrm{~m} \mathrm{~s}^{-1}$. Figure 10a shows an example of the spatiotemporal distribution of wind velocity, where the atmospheric internal wave was observed since 05:30 LT for about $40 \mathrm{~min}$ and the averaged wind velocity was about $5.5 \mathrm{~m} \mathrm{~s}^{-1}$. According to the data in Fig. 10b, the period and amplitude of the wave were, respectively, $9 \mathrm{~min}$ and $0.9 \mathrm{~m} \mathrm{~s}^{-1}$. Two jet streams were also observed for $5 \mathrm{~h}$; one at a height of approximately $200 \mathrm{~m}$ a.g.l. and another at a height of $500 \mathrm{~m}$ a.g.l. and higher.

Figure 11 depicts the spatio-temporal distributions of wind and the signal-to-noise ratio in the evening of 14 August for about $45 \mathrm{~min}$. Here we see one jet stream at a height $\sim 730 \mathrm{~m}$ a.g.l. and an atmospheric internal wave. In the layer of 100-500 m a.g.l., the oscillations of the wind speed, direction and vertical component are accompanied by periodic variations of the signal-to-noise ratio SNR. It is known that SNR is proportional to the attenuated backscatter coefficient $\widetilde{\beta}_{\pi}=\beta_{\pi} \exp \left[-2 \int_{0}^{R} d R^{\prime} \beta_{t}\left(R^{\prime}\right)\right]$, where $\beta_{\pi}$ is the backscatter 
coefficient at range $R$ and $\beta_{t}$ is the radiation extinction coefficient due to absorption and scattering by air molecules and aerosol particles. For range $R \leq 250 \mathrm{~m}$, the effect of turbulent pulsations of the refractive index of air on the intensity of the laser beam focused at a distance of $800 \mathrm{~m}$ (see Table 2) can be neglected. Therefore, for such ranges, the SNR also does not depend on turbulent pulsations of the refractive index. We used the data of Fig. 11d for a height of $220.8 \mathrm{~m}$ ag.l. and calculated the relative variations of the attenuated backscatter coefficient $\eta(t)=\left[\widetilde{\beta}_{\pi}(t)-<\widetilde{\beta}_{\pi}>_{T}\right] /<\widetilde{\beta}_{\pi}>_{T}$ as

$\eta(t)=\left[\mathrm{S} \overline{\mathrm{N}} \mathrm{R}(t)-<\mathrm{S} \overline{\mathrm{N}} \mathrm{R}>_{T}\right] /<\mathrm{S} \overline{\mathrm{N}} \mathrm{R}>_{T}$,

where the operator $\langle\ldots\rangle_{T}$ denotes the time averaging for the period of $45 \mathrm{~min}$.

Since the SNR oscillates within the height (a.g.l.) range $100-500 \mathrm{~m}$ in Fig. 11d, it is evident, that the backscatter coefficient $\widetilde{\beta}_{\pi}$ should vary with time too. These attenuated backscatter coefficient (SNR) variations can be caused by oscillations of the vertical component of the wind velocity vector, with a relatively high amplitude. To test it, we compared $V_{z}(t)$ with $\eta(t)$.

Figure 12 shows the temporal profiles $V_{z}(t)$ and $\eta(t)$ obtained from the data depicted in Fig. 11 for a height of $220.8 \mathrm{~m}$ a.g.1. From the analysis of the curve in Fig. 12a, it follows that the period of oscillations $T_{v}$ of the vertical component of wind velocity is $6.5 \mathrm{~min}$. The same period of oscillations is also observed for other components of the wind vector, with a phase that is shifted by $90^{\circ}$ about the phase of $\widetilde{V}_{z}(t)$. According to Fig. $12 \mathrm{~b}, \eta(t)$ is characterised not only by periodic variations with time, but also by non-stationarity within the considered time interval. It follows from the rough estimates that the period of oscillations of the backscatter coefficient is close to $T_{v}=6.5 \mathrm{~min}$, while the phase is shifted by 90 degrees about the phase of $\widetilde{V}_{z}(t)$.

In addition to these three cases of AIW occurrence, we succeeded in observing this phenomena 3 times more for the period of measurements. Thus, on 25 August before dawn (04:30-05:06 LT), two jet streams and AIW with the period $T_{v} \approx 9 \mathrm{~min}$ and the amplitude $A_{x} \approx 1 \mathrm{~m} \mathrm{~s}^{-1}$ at a height of $402.7 \mathrm{~m}$ a.g.l. were observed in the atmospheric boundary layer. The next day (26 August 2015), the internal wave with the period $T_{v} \approx 18 \min$ and the amplitude $A_{x} \approx 0.7 \mathrm{~m} \mathrm{~s}^{-1}$ at the same height $402.7 \mathrm{ma}$ a.g.l., passed from 16:22 to 19:00 LT. On the same day, the AIW with the halved pe$\operatorname{riod}\left(T_{v} \approx 9 \mathrm{~min}\right)$ and the amplitude $A_{x} \approx 0.4 \mathrm{~m} \mathrm{~s}^{-1}$ at the height $402.7 \mathrm{~m}$ a.g.l. was observed $50 \mathrm{~min}$ later from 19:50 to $20: 35 \mathrm{LT}$.

\section{Summary}

Thus, the results of the experimental campaign in the coastal zone of Lake Baikal on August 2015 show that the raw data from measurements by the Stream Line lidar allow us to visualise the spatio-temporal structure of the wind field in the

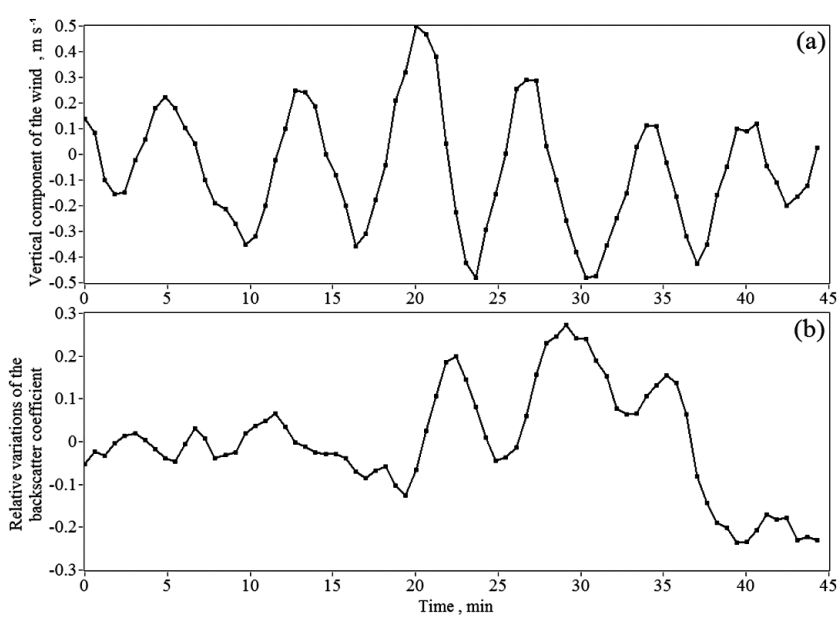

Figure 12. Time dependence of the vertical component of the wind vector (a) and relative variations of the attenuated backscatter coefficient (b) obtained from the data depicted in Fig. 11c, d at a height of $220.8 \mathrm{~m}$ a.g.1.

atmospheric boundary layer and reveal the presence of lowlevel jet streams and atmospheric internal waves. The distinguishing feature of the atmospheric conditions of the Lake Baikal is the occurrence of the stable thermal stratification in the ABL during the daytime. The low-level jet streams were observed during day and night while none of the AIWs events were observed at night-time.

A total of six cases of AIW formation have been revealed, which always occurred in the presence of one or two (in five out of six cases) narrow jet streams at heights of about 200 and $700 \mathrm{~m}$ a.g.l. When two jet streams were formed, the period of oscillations of the wave addend of the wind vector components was $9 \mathrm{~min}$. In only one case it was about $18 \mathrm{~min}$. In the presence of a single jet stream (at a height of $730 \mathrm{~m}$ a.g.l.), the period of oscillations of the wind vector components during AIW was about $6.5 \mathrm{~min}$. The amplitude of oscillations of the horizontal wind components was most often about $1 \mathrm{~m} \mathrm{~s}^{-1}$, while the amplitude of oscillations of the vertical velocity was 3 times smaller. In most cases, the internal waves were observed for $45 \mathrm{~min}$ ( 5 oscillations with the period $\left.T_{v}=9 \mathrm{~min}\right)$. Only once the lifetime of the atmospheric internal wave was about $4 \mathrm{~h}$.

\section{Data availability}

All the data presented in this study are available from the authors upon request.

Acknowledgements. The authors are thankful to A. V. Falits and A. A. Sukharev for the measurements. The authors are grateful to the Institute of Solar-Terrestrial Physics SB RAS for the possibility of using the territory of the Baikal Observatory for the measurements. 
This study was supported by the Russian Science Foundation, Project No. 14-17-00386.

Edited by: M. Kulie

Reviewed by: two anonymous referees

\section{References}

Banakh, V. A., Brewer, V. A., Pichugina, E. L., and Smalikho, I. N.: Measurements of wind velocity and direction with coherent Doppler lidar in conditions of a weak echo signal, Atmos. Oceanic Optics, 23, 381-388, doi:10.1134/S1024856010050076, 2010.

Banakh, V. and Smalikho, I.: Coherent Doppler Wind Lidars in a Turbulent Atmosphere, Artech House Publishers, ISBN-13: 9781-60807-667-3, 2013.

Banakh, V. A., Smalikho, I. N., Falits, A. V., Belan, B. D., Arshinov, M. Y., and Antokhin, P. N.: Joint radiosonde and Doppler lidar measurements of wind in the boundary layer of the atmosphere, Atmos. Oceanic Optics, 28, 185-191, doi:10.1134/S1024856015020025, 2015.

Baumgarten, G., Fiedler, J., Hildebrand, J., and Lübken, F.-J.: Inertia gravity wave in the stratosphere and mesosphere observed by Doppler wind and temperature lidar, Geophys. Res. Lett., 42, 10929-10936, doi:10.1002/2015GL066991, 2015.

Benediktov, E. A., Belikovich, V. V., Bakhmet'eva, N. V., and Tolmacheva, A. V.: Seasonal and daily variations of the velocity of vertical motions at altitudes of the mesosphere and lower thermosphere near Nizhny Novgorod, Geomagn. Aeron., 37, 88-94, 1997.

Chouza, F., Reitebuch, O., Jähn, M., Rahm, S., and Weinzierl, B.: Vertical wind retrieved by airborne lidar and analysis of island induced gravity waves in combination with numerical models and in situ particle measurements, Atmos. Chem. Phys., 16, 46754692, doi:10.5194/acp-16-4675-2016, 2016.

Chunchuzov, I., Vachon, P., and Li, X.: Analysis and modeling of atmospheric gravity waves observed in Radarsat SAR images, Remote Sens. Environ., 74, 343-361, 2000.

German, M. A.: Space Methods of Investigation in Meteorology, Gidrometeoizdat Publishers, 1985 (in Russian).

Kozhevnikov, N. N.: Perturbations of the atmosphere at a flow around mountains, Nauchnyi Mir Publishers, ISBN-13: 5-89176059-2, 1999 (in Russian).

Li, X., Zheng, Q., Pichel, W. G., Yan, X.-H., Liu, W. T., and Clemente-Colon, P.: Analysis of coastal lee waves along the coast of Texas observed in advanced very high resolution radiometer images, J. Geophys. Res., 106, 7017-7025, doi:10.1029/1999JC000019, 2001.

Lyulyukin, V. S., Kallistratova, M. A., Kouznetsov, R. D., Kuznetsov, D. D., Chunchuzov, I. P., and Chirokova, G. Y.: Internal gravity-shear waves in the atmospheric boundary layer from acoustic remote sensing data, Izv. Atmos. Ocean. Phys., 51, 193202, 2015.

Makarenko, N. I. and Maltseva, J. L.: Interference of lee waves over mountain ranges, Nat. Hazards Earth Syst. Sci., 11, 27-32, doi:10.5194/nhess-11-27-2011, 2011.

Manninen, A. J., O'Connor, E. J., Vakkari, V., and Petäjä, T.: A generalised background correction algorithm for a Halo Doppler li- dar and its application to data from Finland, Atmos. Meas. Tech., 9, 817-827, doi:10.5194/amt-9-817-2016, 2016.

Newsom, R. K. and Banta, R. M.: Shear-flow instability in the stable nocturnal boundary layer as observed by Doppler lidar during CASES-99, J. Atmos. Sci., 60, 16-33, 2003.

O'Connor, E. J., Illingworth, A. J., Brooks, I. M., Westbrook, C. D., Hogan, R. J., Davies, F., and Brooks, B. J.: A Method for estimating the turbulent kinetic energy dissipation rate from a vertically pointing Doppler lidar, and independent evaluation from balloon-borne in situ measurements, J. Atmos. Ocean. Tech., 27, 1652-1664, doi:10.1175/2010JTECHA1455.1, 2010.

Päschke, E., Leinweber, R., and Lehmann, V.: An assessment of the performance of a $1.5 \mu \mathrm{m}$ Doppler lidar for operational vertical wind profiling based on a 1-year trial, Atmos. Meas. Tech., 8, 2251-2266, doi:10.5194/amt-8-2251-2015, 2015.

Pearson, G., Davies, F., and Collier, C.: An Analysis of the Performance of the UFAM Pulsed Doppler Lidar for Observing the Boundary Layer, J. Atmos. Ocean. Tech., 26, 240-250, doi:10.1175/2008JTECHA1128.1, 2009.

Plougonven, R. and Zhang, F.: Internal gravity waves from atmospheric jets and fronts, Rev. Geophys., 52, 33-76, doi:10.1002/2012RG000419, 2014.

Román-Cascón, C., Yagüe, C., Mahrt, L., Sastre, M., Steeneveld, G.-J., Pardyjak, E., van de Boer, A., and Hartogensis, O.: Interactions among drainage flows, gravity waves and turbulence: a BLLAST case study, Atmos. Chem. Phys., 15, 9031-9047, doi:10.5194/acp-15-9031-2015, 2015.

Sathe, A. and Mann, J.: Measurement of turbulence spectra using scanning pulsed wind lidars, J. Geophys. Res., 117, D01201, doi:10.1029/2011JD016786, 10329-10330, 2012.

Smalikho, I.: Techniques of wind vector estimation from data measured with a scanning coherent Doppler lidar, J. Atmos. Ocean. Tech., 20, 276-291, 2003.

Smalikho, I. N. and Banakh, V. A.: Estimation of aircraft wake vortex parameters from data measured with a $1.5 \mu \mathrm{m}$ coherent Doppler lidar, Opt. Lett., 40, 3408-3411, doi:10.1364/OL.40.003408, 2015a.

Smalikho, I. N. and Banakh, V. A.: Estimation of aircraft wake vortex parameters from data measured by a Stream Line lidar, in: Proceedings of SPIE 21st International Symposium "Atmospheric and Ocean Optics: Atmospheric Physics", 9680, $968037-$ 1-968037-7, doi:10.1117/12.2205281, 2015b.

Smalikho, I. N., Banakh, V. A., Falits, A. V., and Rudi, Y. A.: Determination of turbulence energy dissipation rate from data measured by the Stream Line lidar in the atmospheric surface layer, Atmos. Oceanic Optics, 28, 980-987, doi:10.15372/AOO20151006, 2015a (in Russian).

Smalikho, I. N., Banakh, V. A., Holzäpfel, F., and Rahm, S.: Estimation of aircraft wake vortex parameters from the array of radial velocities measured by a coherent Doppler lidar, Atmos. Oceanic Optics, 28, 742-750, doi:10.15372/AOO20150801, 2015b (in Russian)

Smalikho, I. N., Banakh, V. A., Holzäpfel, F., and Rahm, S.: Method of radial velocities for the estimation of aircraft wake vortex parameters from data measured by coherent Doppler lidar, Opt. Express, 23, A1194-A1207, doi:10.1364/OE.23.0A1194, 2015 c.

Spiridonov, Y. G., Pichugin, A. P., and Shestopalov, V. P.: Space radar observation of atmospheric internal gravity waves, FEAS USSR, 296, 317-320, 1987 (in Russian). 
Sun, J., Nappo, C. J., Mahrt, L., Belušić, D., Grisogono, B., Stauffer, D. R., Pulido, M., Staquet, C., Jiang, Q., Pouquet, A., Yagüe, C., Galperin, B., Smith, R. B., Finnigan, J. J., Mayor, S. D., Svensson, G., Grachev, A. A., and Neff, W. D.: Review of waveturbulence interactions in the stable atmospheric boundary layer, Rev. Geophys., 53, 956-993, doi:10.1002/2015RG000487, 2015.

Vakkari, V., O’Connor, E. J., Nisantzi, A., Mamouri, R. E., and Hadjimitsis, D. G.: Low-level mixing height detection in coastal locations with a scanning Doppler lidar, Atmos. Meas. Tech., 8, 1875-1885, doi:10.5194/amt-8-1875-2015, 2015.

van Dinther, D., Wood, C. R., Hartogensis, O. K., Nordbo, A., and O'Connor, E. J.: Observing crosswind over urban terrain using scintillometer and Doppler lidar, Atmos. Meas. Tech., 8, 19011911, doi:10.5194/amt-8-1901-2015, 2015.
Vel'tishchev, N. F. and Stepanenko, V. M.: Mesometeorological Processes, Moscow State University Publishers, ISBN-13: 9785-89575-118-3, 2006 (in Russian).

Vinnichenko, N. K., Pinus, N. Z., Shmeter, S. M., and Shur G. N.: Turbulence in the Rree Atmosphere, edited by: Dutton, J. A., Consultants Bureau, 262 pp., ISBN-13: 978-1-4757-0100-5, 1973.

Wang, Y., Creegan, E., Felton, M., Ligon, D., and Huynh, G.: Investigation of nocturnal low-level jet-generated gravity waves over Oklahoma City during morning boundary layer transition period using Doppler wind lidar data, J. Appl. Remote Sens., 7, 1-14, doi:10.1117/1.JRS.7.073487, 2013. 